\title{
Early Satiety - An Unusual Cause
}
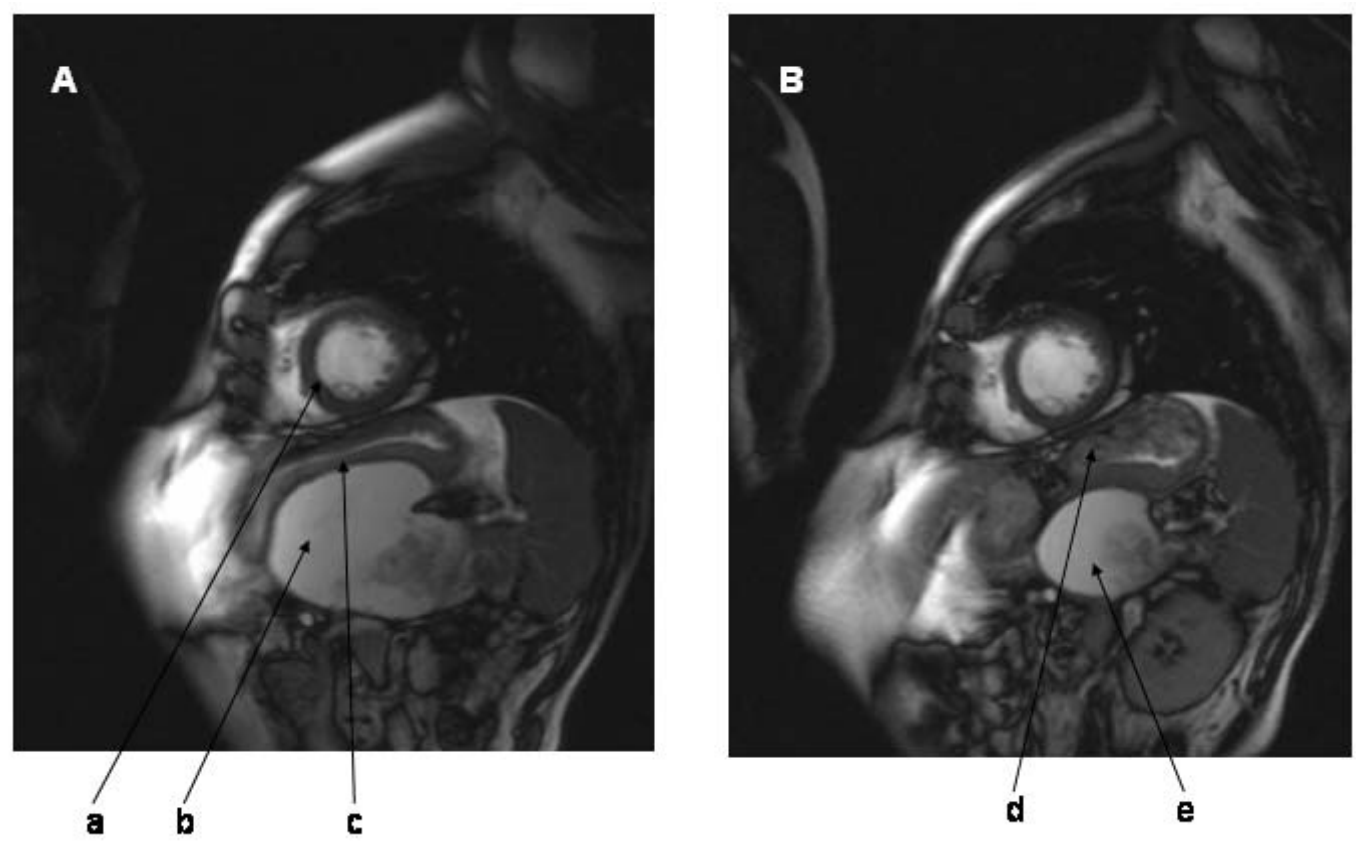

Figure 1A. Short-axis retro cine image through the mid-left ventricular cavity (a). A large pseudocyst (b) is seen within the lesser peritoneal sac, compressing the empty stomach (c). Figure 1B. The same MRI slice taken after three months of conservative treatment shows a significant reduction in the size of the pseudocyst (e). More space is afforded for gastric expansion as demonstrated by visible food contents within the stomach (d).

\section{Robin Anthony Patrick Weir ${ }^{1, *}$ and Nigel McMillan ${ }^{2}$ \\ ${ }^{1}$ Department of Cardiology and ${ }^{2}$ Department of Radiology, Western Infirmary, Glasgow, Scotland, U.K.}

E-mail: robinweir75@hotmail.com; nigel.mcmillan@northglasgow.scot.nhs.uk

Received September 15, 2006; Accepted October 15, 2006; Published October 25, 2006

KEYWORDS: pancreatic pseudocyst, cardiac magnetic resonance, imaging techniques

A 50-year-old man with a history of alcohol excess presented 4 weeks after an acute flare of his known chronic pancreatitis with an inferoposterior myocardial infarction (MI). Systemic enquiry revealed recent weight loss and early satiety. Following percutaneous treatment of the acute infarct, the patient underwent a cardiac magnetic resonance scan (CMR) as part of a clinical trial (1.5T Siemens Sonata). Cine images through the mid-left ventricle revealed an extensive pancreatic pseudocyst measuring $9.1 \times 6.9 \mathrm{~cm}$, 
displacing the (empty) stomach anteriorly and providing a possible explanation for the early satiety (Fig. 1A).

The most appropriate management of pancreatic pseudocyst - open surgery, percutaneous drainage, or conservative management - is subject to ongoing debate[1,2,3]. Conservative management, at least in the short term, was deemed the most pragmatic approach in view of the recent extensive MI. A second CMR scan 3 months later (Fig. 1B), performed 30 min after a meal - gastric contents visible indicated that the pseudocyst had reduced in size, affording more room for gastric expansion. The patient's weight had improved and the early satiety had resolved.

While gastric compression is a recognised anatomical consequence of a large pseudocyst, it is rarely clinically symptomatic. This case clearly displays the anatomical and functional consequences of gastric compression by a moderate pancreatic pseudocyst, and their resolution with conservative management only.

\section{REFERENCES}

1. Varadarajulu, S. (2006) Non-operative management of pancreatic pseudocysts: there is still a role. Ann. Surg. 244(1), 161-162.

2. $\quad$ Andersson, B., Nilsson, E., Willner, J., and Andersson, R. (2006) Treatment and outcome in pancreatic pseudocysts. Scand. J. Gastroenterol. 41(6), 751-756.

3. Schlosser, W., Siech, M., and Beger, H.G. (2005) Pseudocyst treatment in chronic pancreatitis--surgical treatment of the underlying disease increases the long-term success. Dig. Surg. 22(5), 340-345.

This article should be cited as follows:

Weir, R.A.P. and McMillan, N. (2006) Early satiety — an unusual cause. TheScientificWorldJOURNAL 6, 1373-1374. DOI 10.1100/tsw.2006.245. 


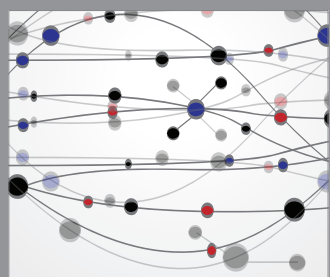

The Scientific World Journal
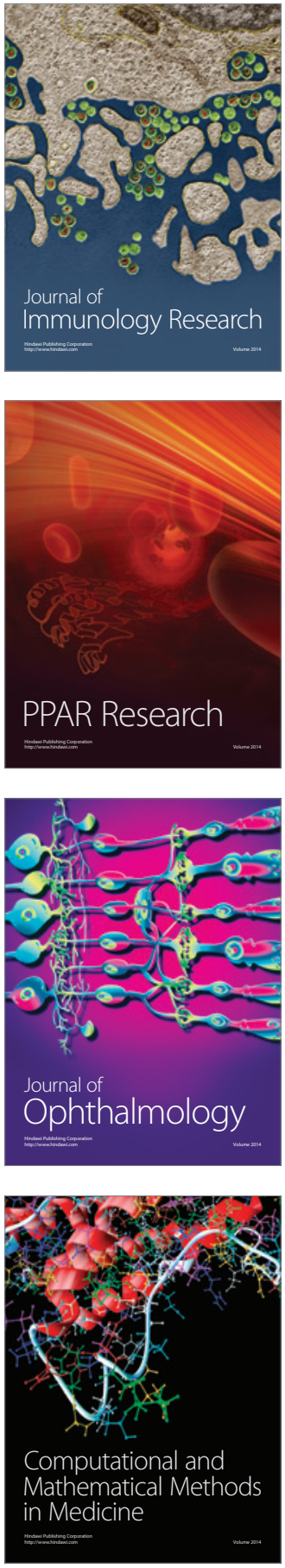

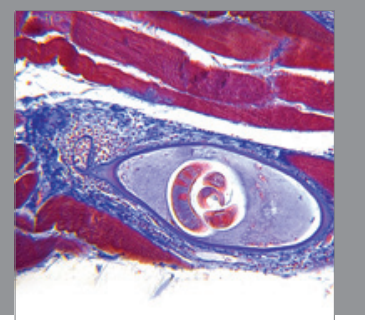

Gastroenterology

Research and Practice
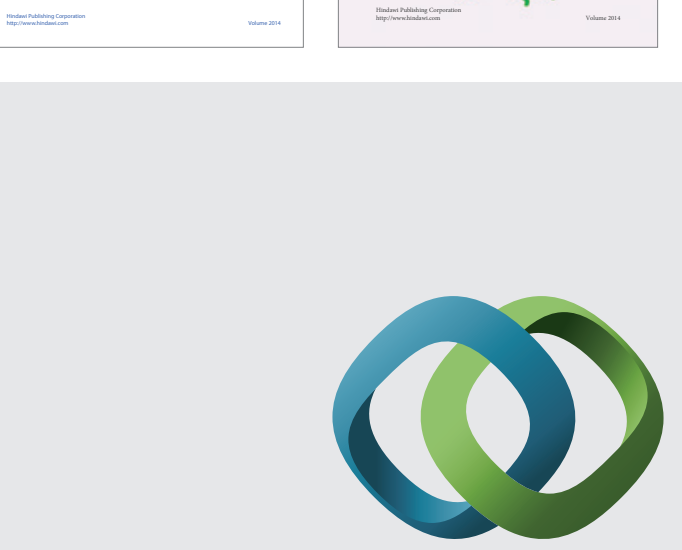

\section{Hindawi}

Submit your manuscripts at

http://www.hindawi.com
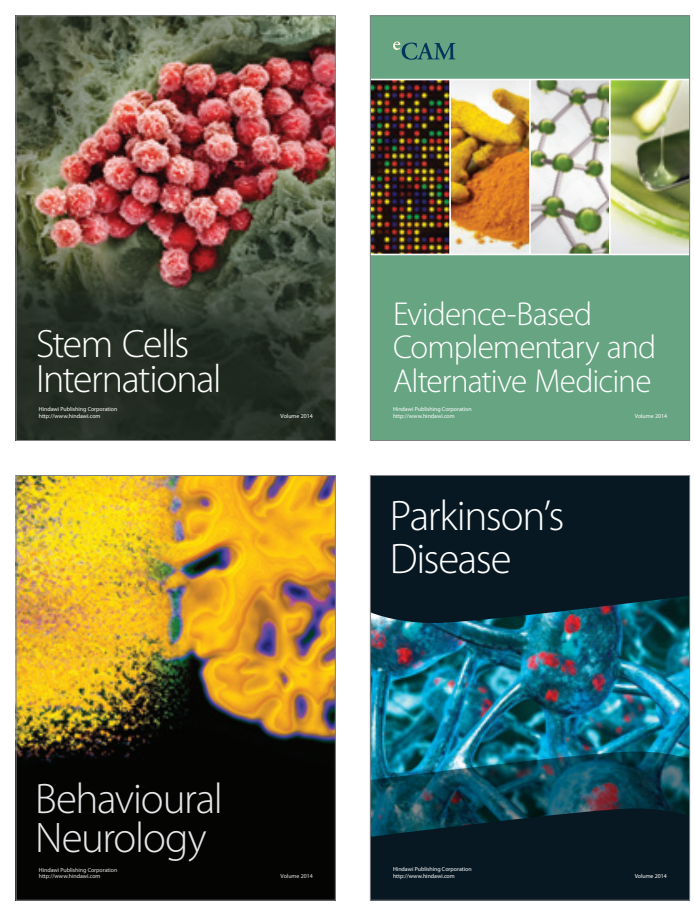

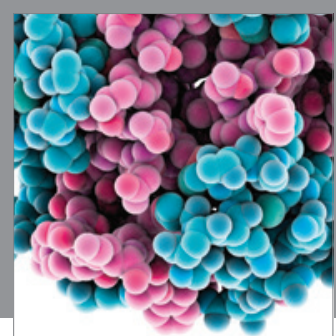

Journal of
Diabetes Research

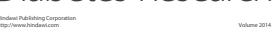

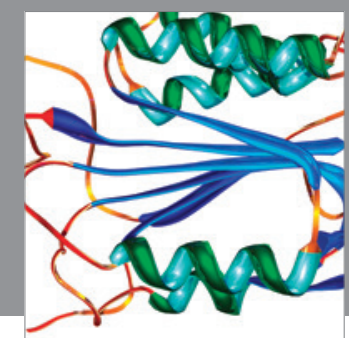

Disease Markers
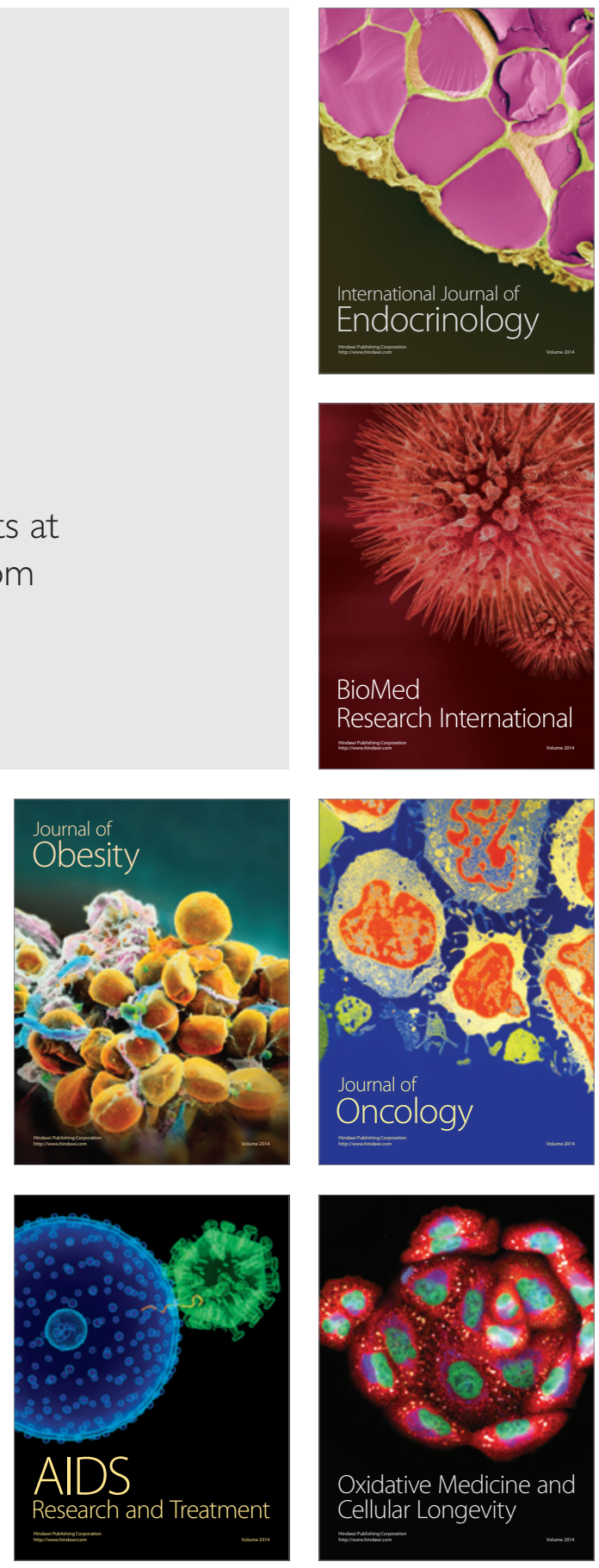